Tropical Journal of Pharmaceutical Research October 2017; 16 (10): 2359-2364

ISSN: $1596-5996$ (print); 1596-9827 (electronic)

(C) Pharmacotherapy Group, Faculty of Pharmacy, University of Benin, Benin City, 300001 Nigeria.

All rights reserved.

Available online at http://www.tjpr.org

Original Research Article

http://dx.doi.org/10.4314/tjpr.v16i10.7

\title{
Preparation and characterization of artemether inclusion complexes with hydroxypropyl- $\beta$-cyclodextrin
}

\author{
Zwanden Sule Yahaya ${ }^{1 *}$, Kenneth C Ofokansi ${ }^{2}$, Suzane T Allagh ${ }^{3}$ and Pat G \\ Bhatia $^{3}$ \\ ${ }^{1}$ Department of Pharmaceutics and Pharmaceutical Microbiology, Faculty of Pharmaceutical Sciences, Kaduna State \\ University, Kaduna, ${ }^{2}$ Department of Pharmaceutics, Faculty of Pharmaceutical Sciences, University of Nigeria, Nsukka. \\ ${ }^{3}$ Department of Pharmaceutics and Pharmaceutical Microbiology, Faculty of Pharmaceutical Sciences, Ahmadu Bello \\ University, Zaria, Nigeria
}

*For correspondence: Email: pharmzwanzy@gmail.com; zwanden.yahaya@kasu.edu.ng; Tel: +234-8060235790

\begin{abstract}
Purpose: To investigate experimentally the inclusion of artemether into the cavity of hydroxypropyl- $\beta$ cyclodextrin and examine its effect on the solubility and dissolution rate of the drug.

Methods: Inclusion complexes of artemether with hydroxypropyl- $\beta$-cyclodextrin of molar ratios 1:1, 1:2 and 1:3 were prepared using the kneading method. Phase solubility analysis and in vitro dissolution studies were utilized in evaluating the influence of inclusion complex formation on the solubility and dissolution rate of the drug. The complexes were characterized using differential scanning calorimetry (DSC) and Fourier transform infrared spectroscopy (FT-IR). The inclusion complex containing equimolar concentrations of artemether and hydroxypropyl- $\beta$-cyclodextrin was then formulated into tablets via direct compression and evaluated for various pharmaceutical characteristics including hardness, friability, absolute drug content and comparative in vitro dissolution profiles with some commercially available brands of artemether.

Results: The phase solubility diagram for the formed complexes in water at $37^{\circ} \mathrm{C}$ indicated a linear curve soluble complex system (referred to as the $A_{L}$ system), and a stability constant $\left(K_{C}\right)$ value of 143 $M^{1}$. Evidence consistent with inclusion complex formation was obtained using FT-IR and DSC. The formulated inclusion complex tablets exhibited a higher rate of dissolution than the pure drug and commercial brands, showing 3.9-, 1.8- and 1.6-fold increases, respectively, over a period of $15 \mathrm{~min}$. Conclusion: Inclusion complexation of artemether with hydroxypropyl- $\beta$-cyclodextrin is a promising approach to enhance the solubility and dissolution rate of the drug.
\end{abstract}

Keywords: Artemether, 2-Hydroxypropyl- $\beta$-cyclodextrin, Dissolution, Solubility enhancement, Inclusion complex

Tropical Journal of Pharmaceutical Research is indexed by Science Citation Index (SciSearch), Scopus, International Pharmaceutical Abstract, Chemical Abstracts, Embase, Index Copernicus, EBSCO, African Index Medicus, JournalSeek, Journal Citation Reports/Science Edition, Directory of Open Access Journals (DOAJ), African Journal Online, Bioline International, Open-J-Gate and Pharmacy Abstracts

\section{INTRODUCTION}

All drugs, regardless of their route of administration, should exhibit at least limited aqueous solubility for therapeutic efficiency. Thus relatively insoluble compounds can exhibit erratic or incomplete absorption, and it might be appropriate to use more soluble salts or chemical derivatives. Complexation, solid dispersion or micronizing techniques might alternatively be employed [1]. Molecular complexation is the interaction between "guest" molecules and cyclodextrins (CD) to form reversible inclusion complex which has been shown to be an effective means of increasing the aqueous solubility of hydrophobic compounds [2]. 
Cyclodextrins are torus shaped molecules of Dglucopyranose obtained by the enzymatic degradation of starch $[2,3]$. There are three types of natural cyclodextrins - alpha ( $\alpha)$, beta $(\beta)$, and gamma (Y) with six, seven and eight glucopyranose units, respectively. The cyclodextrin cavity dimension, which is important for guest-host interaction, ranges from 0.174 to $0.427 \mathrm{~nm}$ for alpha and gamma cyclodextrins respectively $[2,3]$.

Inclusion complex formation is mediated majorly by van der Waals attraction and hydrophobic interaction. The "host," includes, totally or partly, the hydrophobic molecule $[2,3]$.

Artemether is a potent and rapidly acting antimalarial agent available for the treatment of severe multi-resistant malaria and is included in World Health Organization (W.H.O) list of essential medicines [4]. It is active against $P$. vivax as well as chloroquine-sensitive and chloroquine-resistant strains of $P$. falciparum; it is also indicated for the treatment of cerebral malaria [4]. Unfortunately, this potent blood schizonticidal belonging to Class II of Biopharmaceutical Classification System shows poor water solubility and low bioavailability following oral administration [5]. The aim of this study is to utilize 2-hydroxypropyl- $\beta$-cyclodextrin for improving the solubility and dissolution rate of this poorly aqueous soluble drug via inclusion complex formation.

\section{EXPERIMENTAL}

\section{Materials}

2-Hydroxypropyl- $\beta$-cyclodextrin, Molecular weight $(\mathrm{Mw})=1540$ (Sigma-Aldrich, U.S.A), CAS No. 128446-35-5. A pure sample of artemether $(\mathrm{Mw}=298.4$, Batch No. ATM 121003) was a kind donation from Afrab Chem. Nigeria Ltd, Lagos. Other reagents and chemicals were of analytical reagent grade.

Brand A (Coartem ${ }^{\circledR}$ tablets); Batch No. X1571, Manufac. date Jan. 2012, Expiry date Dec. 2013, NAFDAC Reg. No. 04 -275. Manufactured by Beijing Novartis Pharma Ltd, Beijing China.

Brand B (Lumartem ${ }^{\circledR}$ tablets); Batch No.FD2011, Manufac. date Jan. 2012, Expiry date Dec. 2013, NAFDAC Reg. No. A4 -4845. Manufactured by CIPLA Ltd, India.

\section{Spectrophotometric characterization}

The spectrophotometric analysis of artemether in samples was carried out after derivatization.
Derivatization was done by treating samples with $1 \mathrm{M}$ ethanolic hydrochloride and heated at $60^{\circ} \mathrm{C}$ for $3 \mathrm{~h}$, this enabled the formation of acid decomposition product described as $\alpha, \beta$ unsaturated decalone [6-8] which absorbs at 254 $\mathrm{nm}$.

\section{Phase solubility studies and determination of apparent stability constants $\left(\mathrm{K}_{\mathrm{c}}\right)$}

Phase solubility behavior was studied according to the method proposed by Higuchi and Connors [9]. An excess of the drug (200 $\mathrm{mg})$ was added to $20 \mathrm{~mL}$ portions of distilled water in six conical flasks, each containing variable amounts of 2 HP- $\beta-C D(0,3,6,9,12$, and $15 \times 10-3$ moles/Liter). The solutions were shaken on a flask shaker (Grant OLS 200, Cambridge England) for $24 \mathrm{~h}$ at $37 \pm 2{ }^{\circ} \mathrm{C}$, filtered and 100 $\mathrm{mL}$ of $1 \mathrm{M}$ ethanolic $\mathrm{HCl}$ added to $2 \mathrm{~mL}$ of each filtrate and shaken for $5 \mathrm{~s}$. This was heated for 3 $\mathrm{h}$ at $60{ }^{\circ} \mathrm{C}$ and allowed to cool to room temperature. Their absorbance was taken at 254 $\mathrm{nm}$ wavelength.

The solubility of the artemether in every 2 -HP- $\beta$ $C D$ solution was calculated and phase solubility diagram was drawn between the solubility of artemether and different concentrations of 2-HP$\beta$-CD.

The stability constant $\left(\mathrm{K}_{\mathrm{c}}\right)$ of artemether:2-HP- $\beta$ $C D$ complex was calculated using Higuchi and Connor's equation [10].

$$
K_{c}=\frac{\text { slope }}{\text { Intercept }(1-\text { slope })} \ldots \ldots \ldots \ldots \ldots \text { (1) }
$$

\section{Preparation of inclusion complexes in solid state}

This was prepared using artemether and 2hydroxypropyl- $\beta$-cyclodextrin in different molar ratios $(1: 1,1: 2$ and $1: 3 \mathrm{M})$. First, a small quantity of $50 \%$ ethanol was added into cyclodextrin in a glass mortar and triturated until a paste was obtained. Then, the drug was added into the paste and kneaded for $1 \mathrm{~h}$. The product was then air dried at room temperature $\left(28{ }^{\circ} \mathrm{C}\right)$ for $24 \mathrm{~h}$, pulverized, passed through a sieve of size $90 \mu \mathrm{m}$ and stored in a desiccator over fused calcium chloride.

\section{Differential scanning calorimetry}

Thermograms of pure artemether, 2hydroxypropyl- $\beta$-cyclodextrin and inclusion complex were recorded by heating the samples 
at a temperature range of 30 to $300{ }^{\circ} \mathrm{C}$ at a rate of $10^{\circ} \mathrm{C} / \mathrm{min}$.

\section{Fourier transform-infrared spectroscopy (FT- IR)}

The FT-IR spectra of artemether, its complexes, and 2-hydroxypropyl- $\beta$-cyclodextrin were obtained by $\mathrm{KBr}$ pellet method using FTIR spectrophotometer (SHIMADZU FTIR 8400S) over the range $500-4,500 \mathrm{~cm}^{-1}$.

\section{Formulation of artemether-cyclodextrin inclusion complex tablets}

Inclusion complex of artemether-cyclodextrin of molar ratio 1:1 was used for the preparation of tablets. The complex of artemether: 2-HP- $\beta-C D$ containing the equivalent of $20 \mathrm{mg}$ artemether was compressed into tablets by direct compression method. The complex, maize starch and microcrystalline cellulose were mixed together after which talc and magnesium stearate were added and further mixed for $5 \mathrm{~min}$. The mixture was then compressed into tablets (using a compression force of 10.5 metric ton and a punch size of $12.5 \mathrm{~mm}$ ). The tablets were evaluated for thickness, diameter, weight uniformity, crushing strength, friability, disintegration and dissolution time.

\section{In vitro dissolution studies for artemether-CD inclusion complex tablets}

In vitro dissolution of artemether inclusion complex tablets containing $20 \mathrm{mg}$ of artemether was studied in Erweka dissolution apparatus (Erweka DT, Germany). Five hundred millilitres of simulated gastric fluid was used as dissolution medium. The basket was rotated at $50 \mathrm{rpm}$ and the temperature of dissolution medium maintained at $37.0 \pm 0.5 \stackrel{\circ}{\circ} \mathrm{C}$. Five millilitre aliquots were withdrawn at predetermined intervals $(5,10,15,30,45,60,75,90,105$ and $120 \mathrm{~min}$ ) and filtered using Whatman filter paper no. 41. At each interval, withdrawn volume was replaced with a fresh quantity of dissolution medium. After suitable dilution, the withdrawn samples were derivatized by treating with $1 \mathrm{M}$ ethanolic hydrochloride and heated at $60^{\circ} \mathrm{C}$ for 3 $\mathrm{h}$, then analyzed spectrophotometrically at $\lambda_{\max }$ of $254 \mathrm{~nm}$. The percentage amount of artemether released was calculated and plotted against time. This was compared with both the dissolution profile of the pure artemether and the commercial products.

\section{Statistical analysis}

The data generated from the various determina- tions were analyzed using SPSS 20.0 software (SPSS, Chicago, IL, USA) and are presented as mean \pm standard deviation (SD). The differences between the data sets were determined using one-way analysis of variance (ANOVA) and $p<0.05$ was considered statistically significant.

\section{RESULTS}

\section{Phase solubility}

The phase solubility diagram gave a straight line with $R^{2}$ value of 0.9963 and $y=0.0014 x+7 E-06$. The phase solubility diagram for the formed complexes in water at $37^{\circ} \mathrm{C}$ indicated a linear curve soluble complexes system (referred to as the $A_{L}$ system) following the Higuchi and Connors classification [11]. A stability constant $\left(\mathrm{K}_{\mathrm{c}}\right)$ value of $143 \mathrm{M}^{-1}$ was obtained.

\section{Thermal characteristics}

The DSC thermograms of the pure drug, the 2hydroxypropyl- $\beta$-cyclodextrin and the prepared inclusion complexes are given in Figure 1.

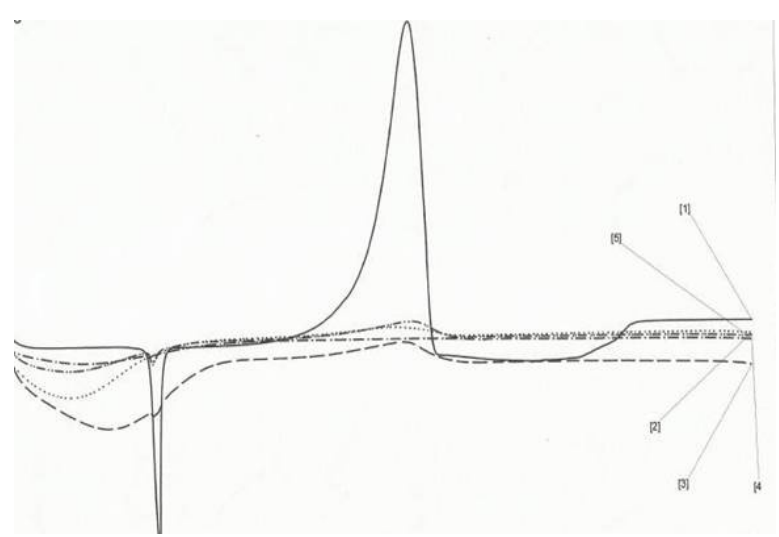

Figure 1: DSC thermograms of pure artemether sample (1), 2-hydroypropyl- $\beta$-cyclodextrin (5), artemether-2-HP- $\beta$-CD (1:1) complex (4), artemether$2-H P-\beta-C D(1: 2)$ complex (2), artemether-2-HP- $\beta$-CD (1:3) complex (3)

The DSC thermogram of pure artemether exhibits a sharp endothermic peak at $89.6^{\circ} \mathrm{C}$ and an exothermic peak at $180{ }^{\circ} \mathrm{C}$, which is consistent with the findings of Yang et al [12]. The 2-hydroxypropyl- $\beta$-cyclodextrin exhibited a typical broad endothermic peak between 50 $100{ }^{\circ} \mathrm{C}$, which attained a maximum at $87.2^{\circ} \mathrm{C}$, consistent with the findings of Liu and Zhu [13].

The DSC thermograms of the inclusion complexes exhibited mark decrease in intensity to even complete disappearance of the artemether endothermic and exothermic peaks. Changes in the exothermic peak (corresponding to its decomposition temperature) ranging from a 
marked reduction in intensity to a complete disappearance suggest that the $2-\mathrm{HP}-\beta-\mathrm{CD}$ artemether complex is more thermally stable than the artemether alone and this further supports the fact that inclusion complex formation enhanced drug stability [14].

\section{Infrared spectra}

The FT-IR spectra of the pure artemether and its inclusion complexes over the frequency range of $500-4500 \mathrm{~cm}^{-1}$ are given in Figure 2. The characteristic FT-IR peaks of the pure artemether occurred at $3198.08 \mathrm{~cm}^{-1}$ due to $\mathrm{O}-\mathrm{H}$ stretching vibration, C-H stretching at $2932.86 \mathrm{~cm}^{-1}, \mathrm{C}-\mathrm{H}$ bending at $1020.38 \mathrm{~cm}^{-1}$, C-O bending at $1020.38 \mathrm{~cm}^{-1}$, C-O-O-C bending vibration at $1195.95 \mathrm{~cm}^{-1}$, O-O-C stretching at $857 \mathrm{~cm}^{-1}$ and $0-O$ stretching at $746 \mathrm{~cm}^{-1}$ respectively. These values are comparable to those earlier reported by Fule et al [15].

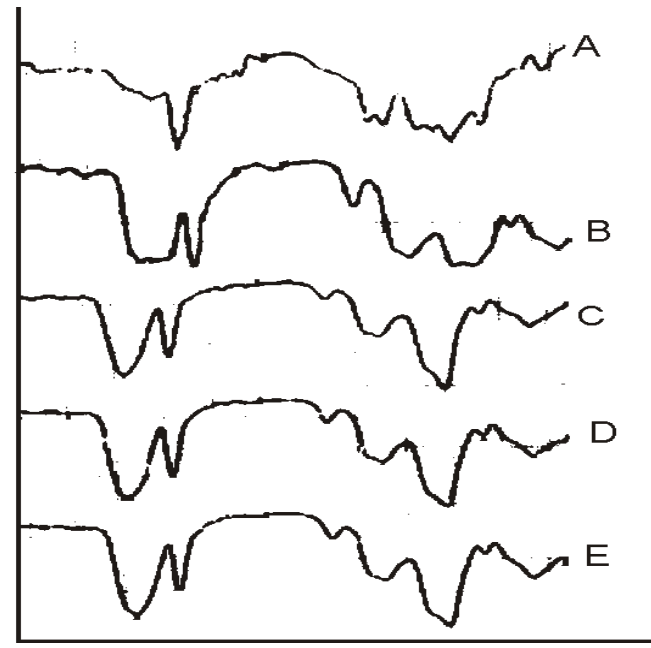

Figure 2: FT-IR spectrum of pure artemether sample $(\mathrm{A})$, 2-hydroypropyl- $\beta$-cyclodextrin (B), artemether-2HP- $\beta$-CD (1:1) complex (C), artemether-2-HP- $\beta-C D$ $(1: 2)$ complex (D) and artemether-2-HP- $\beta$-CD (1:3) complex $(\mathrm{E})$

In the FT-IR spectra of 1:1 $\mathrm{M}$ inclusion complex, the bands of the pure drug due to $\mathrm{O}-\mathrm{H}$ bending and $\mathrm{C}-\mathrm{O}$ bending vibration were shifted to higher frequencies of 3396 and $1037.74 \mathrm{~cm}^{-1}$ respectively while those due to $\mathrm{C}-\mathrm{H}$ stretching and $\mathrm{C}-\mathrm{H}$ bending were shifted to lower frequencies 2930.93 and $1373.36 \mathrm{~cm}^{-1}$ with marked decrease in intensity. In 1:2 M molar inclusion spectra the decrease in peak intensity was more compared to what was observed in the $1: 1 \mathrm{M}$ inclusion complex. In addition, peaks at 3198.08 and $1020.38 \mathrm{~cm}^{-1}$ were shifted to higher frequencies and appeared at 3424 and 1043.32 $\mathrm{cm}^{-1}$ respectively. Those at 2932 and 1449.55 $\mathrm{cm}^{-1}$ were shifted to lower frequencies and appeared at 2928.04 and $1368.54 \mathrm{~cm}^{-1}$ respectively. In addition, there was a disappearance of bands at 4594.59, 4241.61, 4066.08 and $3862.58 \mathrm{~cm}^{-1}$.

For the 1:3 $\mathrm{M}$ inclusion complex spectra, peaks at 3198.08 and $1020.38 \mathrm{~cm}^{-1}$ were equally shifted to higher frequencies while those at 2932.86 and $1449.55 \mathrm{~cm}^{-1}$ were shifted to a lower frequency.

\section{Tablet properties}

The properties for the commercial and prepared tablets of cyclodextrin-artemether inclusion complex are given in Table 1.

For the prepared inclusion complex tablet; the crushing strength was in the range of 10.0-10.5 $\mathrm{kg} / \mathrm{F}$, the percentage friability was 0.048 which is less than $1 \%$ (fulfilling the official requirements), the drug content was $95.5 \%$ and the disintegration time was 9.28 min which is within Pharmacopoeia limits (15 $\mathrm{min}$ for uncoated tablets), [16]. The mean weight of $402.85 \mathrm{mg}$ was within the Pharmacopoeia limits, which specifies that for tablets weight $>250 \mathrm{mg}, \pm 5 \%$ weight variation is allowed [16]. The inclusion complex tablets prepared, therefore, fall within the limit considering the $400 \mathrm{mg}$ theoretical weight.

Table 1: Tablet characteristics of commercial and formulated artemether tablets (mean \pm SEM)

\begin{tabular}{lcccc}
\hline Tablet property & Brand A & Brand B & $\begin{array}{c}\text { Artemether-2- } \\
\text { HP- } \boldsymbol{\beta} \text {-CD } \\
\text { complex (1:1) } \\
\text { tablet }\end{array}$ & P-value \\
\hline Thickness (mm) & & $3.52 \pm 0.01$ & $3.54 \pm 0.02$ & 0.922 \\
Uniformity of weight (mg) & $3.22 \pm 0.01$ & $344.95 \pm 5.17$ & $402.85 \pm 1.39$ & 0.774 \\
Diameter (mm) & $240.65 \pm 0.33$ & $10.09 \pm 0.03$ & $12.07 \pm 0.02$ & 0.612 \\
Crushing strength (kg/F) & $8.88 \pm 0.02$ & $7.40 \pm 0.40$ & $10.90 \pm 0.20$ & 0.193 \\
Drug content (\%) & $11.7 \pm 0.12$ & $97.00 \pm 0.03$ & $95.50 \pm 0.07$ & 0.917 \\
Disintegration time (Min) & $98.5 \pm 0.00$ & $3.30 \pm 0.25$ & $9.28 \pm 0.04$ & $0.003^{* *}$ \\
Friability (\%) & $3.37 \pm 0.03$ & $0.083 \pm 0.001$ & $0.058 \pm 0.001$ & 0.074 \\
\hline ** indicates significance at 5\% level $(P<0.05)$ & $0.048 \pm 0.000$ & & &
\end{tabular}




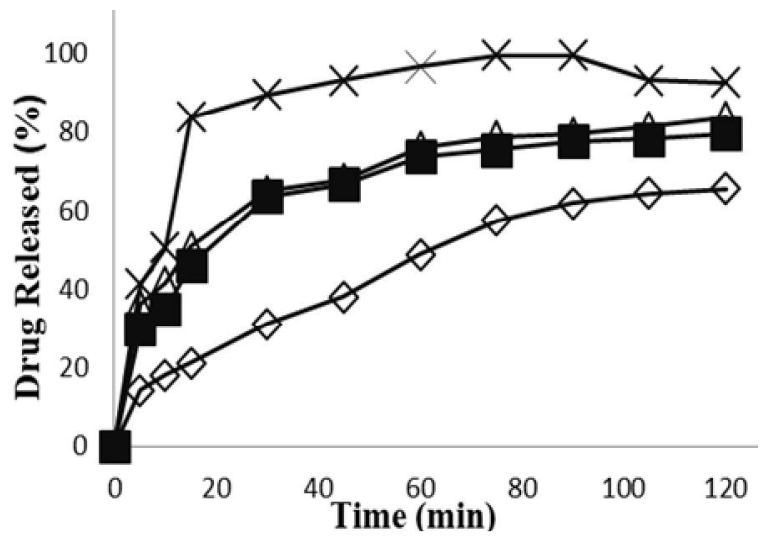

Figure 3: Dissolution profiles of pure artemether $(\diamond)$, brand $A(\Delta)$, brand $B(\boldsymbol{\square})$ and inclusion complex (1:1) tablet $(\mathrm{X})$ in SGF, $\mathrm{pH} 1.2$

\section{Dissolution}

The dissolution profile of the inclusion complex $(1: 1 \mathrm{M})$ tablet, marketed tablets (brands $\mathrm{A}$ and $\mathrm{B}$ ) and the pure drug sample in simulated gastric fluid, pH 1.2 are shown in Figure 3.

\section{DISCUSSION}

The phase solubility diagram showed that the solubility of artemether increased as the concentration of 2-hydroxypropyl- $\beta$-cyclodextrins increased. It further shows that each complex contains only one molecule of the complexing agent. Because the linear host-guest correlation obtained had a slope less than one (1) it suggest that the stoichiometry of the complexes is $1: 1$ $(\mathrm{mol} / \mathrm{mol})$ artemether-2-HP- $\beta-\mathrm{CD}$ [17].

The value of the stability constant $\left(\mathrm{K}_{\mathrm{c}}\right)$ falls within the range of $50-2000 \mathrm{M}^{-1}$ suggesting a favorable interaction that may contribute to the improved dissolution of hydrophobic drugs occurred $[17,18]$. It has been reported that when a guest molecule is incorporated in CD cavity, its physicochemical properties are usually modified $[3,19,20]$.

Earlier reports have shown that inclusion of drugs into cyclodextrin temporarily locked or caged the drug within the host cavity, giving rise to beneficial modifications like solubility enhancement, stabilization of labile guest molecule against oxidation, visible or UV light, heat and so forth [21]. These observations, therefore, clearly indicate strong evidence of inclusion of the drug into the cyclodextrin cavity.

All inclusion complexes (1:1, 1:2 and 1:3 M) exhibited pronounced enhancement with comparable values of dissolution rate; therefore, inclusion complex of molar ratio 1:1 was used for the preparation of tablets since it contains lesser amount of cyclodextrin than complexes of molar ratios $1: 2$ and 1:3. The prepared tablets were of good properties and did not exhibit chipping, capping or sticking. The tested commercial tablets equally conformed to the compendial specifications for uniformity of weight, percentage friability and disintegration time.

The dissolution rates of the inclusion complex tablets (from inclusion complex of 1:1 $\mathrm{M}$ ratio) were found to be higher than that of the commercial brands. Tablets formulated from the inclusion complexes exhibited 3.9-fold, 1.8-fold, and 1.6-fold increases, respectively over the pure sample and the commercial brands $A$ and $B$ in the amount of drug released in $15 \mathrm{~min}$. The amount of artemether dissolved after $45 \mathrm{~min}\left(\mathrm{t}_{45}\right)$ from inclusion complex tablets was $93.1 \%$, while corresponding values of 68 and $67 \%$, respectively, were dissolved from $A$ and $B$. The increased dissolution rate of artemether cyclodextrin inclusion complexes may be attributable to improvement in drug wettability, decrease in drug crystallinity, increase in hydrophilicity or a reduction in the interfacial tension between the drug and the dissolution medium due to the surfactant-like properties of CDs [22].

\section{CONCLUSION}

Molecular inclusion complex formation between $2-H P-\beta-C D$ and artemether has been confirmed with the inclusion complex displaying enhanced solubility of artemether in distilled water. Tablets formulated from $1: 1 \mathrm{M}$ ratio of the artemether-2HP- $\beta-C D$ complex have higher dissolution rate than the selected commercial artemether tablets. Thus, the developed artemether/2-HP- $\beta-C D$ complex can be further explored to develop artemisinin-combination therapies with enhanced bioavailability for more effective treatment of malaria.

\section{DECLARATIONS}

\section{Acknowledgement}

The authors are thankful to the management of Afrab Chem Nigeria Ltd for the kind donation of pure samples of artemether.

\section{Conflict of Interest}

No conflict of interest associated with this work.

\section{Contribution of Authors}

The authors declare that this work was done by 
the authors named in this article and all liabilities pertaining to claims relating to the content of this article will be borne by them.

\section{Open Access}

This is an Open Access article that uses a funding model which does not charge readers or their institutions for access and distributed under the terms of the Creative Commons Attribution License (http://creativecommons.org/licenses/by/ 4.0) and the Budapest Open Access Initiative (http://www.budapestopenaccessinitiative.org/rea d), which permit unrestricted use, distribution, and reproduction in any medium, provided the original work is properly credited.

\section{REFERENCES}

1. York P. Design of dosage forms. In: Aulton, Michael E, Ed. Pharmaceutics: The Design and Manufacture of Medicines, 3rd edn, London: Churchill Livingstone; 2007; pp 10-11.

2. Mansoor, Amiji M. Complexation and protein binding. In: Mansoor AM, Beverly SJ, Eds. Applied Physical Pharmacy. 1st edn, USA: McGraw-Hill Companies; 2003; pp 199-230.

3. Zheng-Yu Jin. Cyclodextrin Chemistry: preparation and application. China: World Scientific Publishing and Chemical Industry Press; 2013; p 541.

4. Medha J, Sulabha $P$, Shobhona $S$, Vandana $P$. Solid microemulsion preconcentrate of artemether for effective treatment of malaria. Int J Pharm 2008; 362: 172-178

5. Renu C, Sushma G, Geeta S, Jain DVS, Raghuvir RSP, Evans CC. Interaction of artesunate with $\beta$-cyclodextrin: Characterization, thermodynamic parameters, molecular modeling, effect of PEG on complexation and antimalarial activity. Res Pharm Sci 2008; 1: 38-48

6. Thomas CG, Ward SA. Selective determination in plasma of artemether and its major metabolitedihydroartemisinin, by high-performance liquid chromatography with ultraviolet detection. J Chromatogr 1992; 583: 131-136.

7. The International Pharmacopoeia (2008), 4th edn (incl 1st Supplement), 202 Hhttp://www.who.int/phint/ accessed on 19th September 2011
8. Shrivastava ABP, Nagori BP. New Simple and Economical Spectrophotometric Method for Estimation of Artemether in Pharmaceutical Dosage Forms. Asian J Res Chem 2008; 1: 19-21.

9. Higuchi $T$, Connors KA. Phase-solubility techniques. Adv Anal Chem Instrum 1965; 4: 117-212.

10. Shankarrao KA, Ghadge DM, Kokate PB. Formulation and in vitro evaluation of orally disintegrating tablets of olanzapine-2-hydroxypropyl- $\beta$-cyclodextrin inclusion complex. Iranian J Pharm Res 2010; 9(4): 335-347.

11. Higuchi T, Connors KA. Phase solubility techniques. Adv Anal Chem Instrum 1965; 4: 117-212.

12. Yang $B$, Jun $L, Y u$ L. Artemether/hydroxypropyl- $\beta$ cyclodextrin host-guest system, Bioorgan Med Chem 2009; 17: 6311-6317.

13. Liu L, Zhu S. Preparation and characterization of inclusion complexes of prazosin hydrochloride with $\beta$ cyclodextrin and hydroxypropyl- $\beta$-cyclodextrin. J Pharmaceut Biomed Analy 2006; 40: 122-127.

14. Chadha R, Gupta $S$, Shukla G, Jain DS, Singh $S$. Characterization, thermodynamic parameters and in vivo antimalarial activity of inclusion complexes of artemether. Drug Dis Ther 2010; 4 (3): 190-120.

15. Fule RA, Meer TS, Sav RA, Amin DP. Dissolution rate enhancement and physicochemical characterization of artemether and lumefantrin solid dispersions. Int J Drug Del 2012; 4: 95-106.

16. British Pharmacopoeia. Vol. I and II; Her Majesty's Stationary Office, University Press, Cambridge; 2002.

17. Loftsson T, Másson M, Brewster ME. Self-association of cyclodextrins and cyclodextrin complexes. J Pharm Sci 2005; 93: 1091-1099.

18. Brewester ME, Loftsson T. Cyclodextrins as pharmaceutical solubilizers. Adv Drug Del Rev 2007; 59: 645-666.

19. Polla GI, Vega DR, Hilda L. Thermal behavior and stability of olanzapine. Int J Pharm 2005; 301: 33-40.

20. Vivek $K$, Reddy $H$, Murthy RR. Investigation of the effect of the solid lipid matrix on drug entrapment, in-vitro release, physical stability of olanzapine-loaded solid lipid nanoparticles. AAPS Pharm Sci Tech 2007; 8: 1-17.

21. Schmid G. Cyclodextrin glucanotransferse production: yield enhancement by overexpression of cloned genes. Trends Biotechnol 1989; 7: 244-248.

22. Lin G, Xu SA. New Method of encapsulating volatile oils in Chinese medicinal herbs with beta-cyclodextrin. Zhongguo Zhongyao Zazhi 1989; 17(5): 283-285. 